TAPROBANICA, ISSN 1800-427X. June, 2014. Vol. 06, No. 01: pp. 12-20, 5 pls.

(C) Research Center for Climate Change, University of Indonesia, Depok, Indonesia

\& Taprobanica Private Limited, Homagama, Sri Lanka

http://www.sljol.info/index.php/tapro

\title{
A NEW CRYPTIC SPECIES OF GECKO OF THE GENUS Hemidactylus Oken, 1817 (REPTILIA: GEKKONIDAE) FROM SOUTHERN INDIA
}

\author{
Zeeshan A. Mirza ${ }^{1, *}$ and Rajesh V. Sanap ${ }^{1}$
}

\footnotetext{
${ }^{1}$ National Centre for Biological Sciences, Tata Institute of Fundamental Research, Bangalore 560065, India

*E-mail: zeeshanm@ncbs.res.in
}

\begin{abstract}
A new species of gecko superficially resembling Hemidactylus maculatus is described from the southern Indian state of Tamil Nadu. Hemidactylus acanthopholis sp. nov. is a large sized Hemidactylus, SVL at least $91.7 \mathrm{~mm}$. Dorsal scalation on trunk granular, intermixed with enlarged, fairly regularly arranged longitudinal rows of 18-20 trihedral, moderately keeled, striated tubercles of equal size on dorso-lateral aspect, 2-3 rows of tubercles on mid-dorsal smaller in size, approximately two dorsal granular scales wide. Two large rounded and one small internasal between nasals. Two pairs of postmentals, anterior pair is twice as long and wide as the posterior pair. Scales on ventral trunk arranged in 35-40 rows. Lamellae divided, 9, 11, 10, 10, 10 on manus, and 10, 12, 12, 12, 12 on pes respectively on digits I-V. Caudal pholidosis on dorsal aspect, consist of small, striated scales intermixed with large rounded un-keeled tubercles, scales sub-equal throughout and a series of large eight enlarged, moderately keeled and weakly striated and flattened tubercles in a whorl on each caudal segment. Femoral pores, 19-21 on each side separated medially by 13-14 pore-less scales.
\end{abstract}

Keywords: biogeography, Hemidactylus maculatus, species-complex, taxonomy, Western Ghats

\section{Introduction}

Hemidactylus is the most species rich gekkonid genus with at least 124 (McMahan \& Zug 2007; Uetz \& Hošek 2013) described species and comprises of at least 25 species in India including $H$. karenorum (Theobald), $H$. robustus Heyden and excluding Dravidogecko anamallensis Günther (Agarwal et al., 2011; Bansal \& Karanth, 2013; Bauer et al., 2010; Bauer et al., 2012; Mahony \& Zug, 2008,
Purkayastha et al., 2010). Members of this genus and in general gekkonids in India are poorly known however, there has been an increased attention towards documentation of diversity of gekkonids evident from the descriptions of five new species of the genus Hemidactylus in the last five years and several taxonomic amendments which include removal and addition of species to the list of Indian 
Hemidactylus (Agarwal et al., 2011; Bauer et al., 2012; Giri, 2008; Giri \& Bauer, 2008, Giri et al., 2009; Mahony, 2009; Purkayastha et al., 2010). Hemidactylus maculatus Duméril \& Bibron, 1836 is a large sized gecko which was thought to be widespread across the Western Ghats and other parts of peninsular India (Smith, 1935); however recent investigations show that $H$. maculatus is a complex of multiple species (Agarwal et al., 2011; Javed et al., 2009, 2011). H. maculatus is now known with certainty only from Northern Western Ghats of Gujarat and Maharashtra; population from south eastern Karnataka and north Tamil Nadu can now be attributed to $H$. graniticolus Agarwal, Giri \& Bauer, 2011 and those from northern Andhra Pradesh represents an undescribed species (Javed et al., 2011; Mahony 2011).

During a recent visit to the Natural History Museum, London, we examined material assigned to the species $H$. maculatus and $H$. hunae Deraniyagala, 1937. As highlighted earlier by Agarwal et al. (2011) and similar doubts by Javed et al. (2011) the material assigned to $H$. hunae represents three forms of which one is the type from Sri Lanka, the second one has been described as $H$. graniticolus by Agarwal et al. (2011) represented by six specimens from Salem, northern Tamil Nadu. Another form, which is represented by three specimens from Tirunelveli District, Tamil Nadu in the collection of the museum, represents yet another undescribed cryptic species which we here describe as a new species based on material from the Natural History Museum, London as well as from the collection of the Bombay Natural History Society, Mumbai and Zoological Survey of India, Kolkata. The new species is compared to Indian and Sri Lankan members of the genus and in particular to those of the $H$. maculatus complex including their synonyms.

\section{Materials and Methods}

All measurements were taken following Giri \& Bauer (2008) with Mitutoyo digital calipers (to the nearest $0.1 \mathrm{~mm}$ ): snout-vent length (SVL, from tip of snout to vent); trunk length (TRL, distance from axilla to groin measured from posterior edge of forelimb insertion to anterior edge of hind limb insertion); body width (BW, maximum width of body); crus length (CL, from base of heel to knee); tail length (TL, from vent to tip of tail); tail width (TW, measured at widest point of tail); head length (HL, distance between retroarticular process of jaw and snout-tip); head width (HW, maximum width of head); head height ( $\mathrm{HH}$, maximum height of head, from occiput to underside of jaws); forearm length (FL, from base of palm to elbow); ear length (EL, longest dimension of ear); orbital diameter (OD, greatest diameter of orbit); nares to eye distance (NE, distance between anteriormost point of eye and nostril); snout to eye distance (SE, distance between anteriormost point of eye and tip of snout); eye to ear distance (EE, distance from anterior edge of ear opening to posterior most edge of orbit); internarial distance (IN, distance between nares); interorbital distance (IO, shortest distance between left and right supraciliary scale rows) (Table 1). Measurements of the digits were recorded from the base of the digit to base of the claw. Meristic counts and external observations of morphology were made using a Wild M5 dissecting microscope. Images of the specimens were taken with a Canon 550D mounted with a Canon $100 \mathrm{~mm}$ macro illuminated with two external Canon 430EX-II flashes and plates were edited in Adobe Photoshop CS5. Morphological data for species was obtained from Agarwal et al. (2011), Amarasinghe et al. (2009), Batuwita \& Pethiyagoda (2012), Smith (1935), and Javed $e t$ al. (2011). Abbreviations for institution used in the manuscript are as follows: BMNH, British Museum of Natural History (UK); BNHS, Bombay Natural History Society, Mumbai (India); CAS, Californian Academy of Sciences, San Francisco (USA); ZSI, Zoological Survey of India, Kolkata (India). List of comparative material examined is presented in Appendix I.

\section{Systematics \\ Hemidactylus acanthopholis sp. nov.} Figs. 1-7 (Plates 3-7), Table 1

Holotype: adult male (91.7mm SVL), BMNH 1946.8.23.68 (74.4.29.1050); Tirunelveli District (=Tinnevelly), Tamil Nadu, India. coll. Colonel R. H. Beddome.

Paratypes: adult male (82.2mm SVL), BMNH 1946.8.23.67 (74.4.29.1049), Tirunelveli District, Tamil Nadu, India. coll. Colonel R. H. Beddome; adult male (108.6mm SVL), ZSI 
12429, Tirunelveli District (=Tinnevelly), Tamil Nadu, India, purchased from E. Gerard; adult female $(85.5 \mathrm{~mm}$ SVL), BMNH 1946.8.23.69 (74.4.29.1051), Tirunelveli District, Tamil Nadu, India, coll. Colonel R. H. Beddome; adult female (79.8mm SVL), BNHS 1670, Kalakad-Mundanthurai Tiger Reserve, Tamil Nadu, India, coll. S. P. Vijayakumar.

Other examined materials: adult male, ZSI 24959a and adult female ZSI 24959b, Pamber, Banatheertham, $16 \mathrm{~km}$ south west of Mundanthurai, Tirunelveli District, Tamil Nadu, India, coll. S. S. Saha, 18 IX 1992; adult males, CAS 104311, CAS 104313 and adult females, CAS 104312, CAS 104314, Courtallam, Tamil Nadu, India, coll. J. C. Daniel, 20 V 1966; juvenile, BNHS 1671, Kalakad-Mundanthurai Tiger Reserve, Tamil Nadu, India, coll. S. P. Vijayakumar.

Diagnosis: A large sized Hemidactylus, SVL at least $91.7 \mathrm{~mm}$. Dorsal scalation on trunk granular, intermixed with enlarged, fairly regularly arranged longitudinal rows of 18-20 trihedral, moderately keeled, striated tubercles of equal size on dorso-lateral aspect, 2-3 rows tubercles on mid-dorsal smaller in size of about two dorsal granular scale wide. Two large rounded and one small internasal between nasals. Two pair of postmentals, anterior pair is twice as long and wide as the posterior pair. Scales on trunk venter arranged in 35-40 rows. Lamellae divided, 9, 11, 10, 10, 10 on manus and $10,12,12,12,12$ on pes. Caudal pholidosis, dorsal aspect, small, striated scales intermixed with large rounded un-keeled tubercles, scales sub-equal throughout and a series of eight enlarged, moderately keeled and weakly striated and flattened tubercles. Femoral pores $19-21$ on each side separated medially by 13-14 pore-less scales.

Description of the holotype: Holotype in a fairly good state, preserved in a ' $\mathrm{C}$ ' shaped loop (Fig. 1); tail broken and partly regenerated; a longitudinal midventral incision; dorsum greyish brown lacking distinct markings except for vestigial faint undulating bands on the trunk, perhaps due to long preservation.

A large sized gecko (SVL $91.7 \mathrm{~mm}$ ) with a large head (HL/SVL ratio 0.23); head as long as wide (HW/HL ratio 1.0), slightly depressed
(HH/HL ratio 0.58), distinct from neck (Fig. 2A); loreal region slightly inflated; canthus rostralis moderately inflated; snout relatively short (SE/HW ratio 0.56) and obtusely pointed at lateral view, longer than eye diameter (OD/SE ratio 0.52); scales on snout and forehead large, circular as well as oval, granular and juxtaposed; scales on snout larger than those on occipital region; scales enlarged, round, slightly depressed between eye and ear; four large, un-keeled, slightly depressed tubercles present on the upper and anterior border of the ear; eyes large (OD/HL ratio 0.29 ); pupil vertical and dilated with crenulated margins; supraciliaries small, pointed, anteriormost are slightly larger; ear-opening large, suboval, slightly oblique, its length more than half of diameter of eye (EL/OD ratio 0.53), ears lacking lobules; eye to ear distance greater than diameter of eye (EE/OD ratio 1.14); rostral quadrangular, much wider than deep; divided by a suture dorsomedially for $1 / 3$ of its length; rostral in contact with nasal, first supralabial, one supranasal and internasals; two large and one small internsal present between supranasals; nasals circular and in touch with rostral, one enlarged supranasal, and two postnasals; mental triangular, larger than postmentals; two pairs of postmentals, anterior pair twice as long and wide as the posterior pair and in contact with each other; anterior postmentals in touch with mental, infralabials, posterior postmentals; posterior postmental pair relatively small, separated and less than half the size of anterior postmentals; supralabials are separated from orbit by two scale rows; supralabials (to midorbital position) eight on each side; supralabials (to angle of jaw) ten on each side; infralabials (to angle of jaw) eight on each side.

Body moderately elongate (TRL/SVL ratio 0.39 ) and dorsoventrally flattened, with conspicuous ventrolateral furrow; dorsal scalation on trunk, granular, intermixed with enlarged, fairly regularly arranged longitudinal rows of 18-20 trihedral, moderately keeled, striated tubercles of equal size on dorso-lateral aspect, 2-3 rows tubercles on mid-dorsal smaller in size at about two dorsal granular scales wide, trihedral scales at the first segment of tail is larger than dorsum of trunk; ventral scales much larger than dorsal, smooth, flat, round; mid body scales across belly 38-40; gular region with much smaller, uniform, 
granular scales; 19 (left) and 20 (right) femoral pores, separated at mid-pelvic region by 14 pore-less scales; dorsal region of manus and pes possess larger, keeled trihedral tubercles intermixed with small flat scales, while ventral region has only small, smooth and flat scales. Limbs short, stout; digits short, moderately dilated, bearing slightly oblique lamellae on the ventral surface, clawed; forelimbs short (FL/SVL ratio 0.16), slightly leaner in comparison with hindlimbs (CL/SVL ratio 0.18 ); all digits of manus and digits I-IV of pes indistinctly webbed at the base, terminal phalanx of all digits curved, arising angularly from distal portion of expanded lamellar pad, free distal phalanx of digit I of pes not half as long as the dilated portion. First digit of pes is more than half the size of second digit; lamellae beneath the digits, both left and right manus 10 , $11,11,11,11$; left pes $10,11,11,11,10$, right pes $10,11,11,11,11$. Relative length of digits is, IV $>$ V $>$ III $>$ II $>$ I (left manus); IV $>$ III $>$ V $>$ II $>$ I (left pes).

Tail moderately depressed, oval in cross section, longer than snout-vent length (TL/SVL ratio 1.24). Caudal segmentation distinct; pholidosis: small, imbricate, striated scales intermixed with large rounded un-keeled tubercles; scales sub-equal throughout and a series of eight enlarged, moderately keeled and weakly striated and flattened tubercles on segment one, remainder of the segments bearing only six large keeled trihedral tubercles (arranged in two groups of three scales with a distinct median space) posteriorly oblique. Scales of median subcaudal series smooth, each much wider than long; scales of postcloacal region and on proximal part of tail base slightly overlapping, larger than on rest of dorsal portion of the tail.

Etymology: The specific epithet 'acanthopholis' means spiny scales which refer to the large keeled dorsal tubercles.

Variation in paratypes: Morphometric and meristic data presented in Table 1 . The paratypes morphologically match the holotype with the exception of the following: (i) Femoral pores 19 (left) and 21 (right) in paratype male BMNH 1946.8.23.67 separated medially by 13 pore-less scales; 21 (both left and right) in paratype male ZSI 12429 separated medially by 12 pore-less scales; (ii) Lamellae on left manus of male paratype BMNH 1946.8.23.67 is 1011-11-11-12; (iii) Lamellae on pes of female paratype BMNH 1946.8.23.69 are 9, 11, 12, 12, 11 (left), and 9, 11, 11, 10, 11 (right); (iv) Female paratype BMNH 1946.8.23.69 is slightly darker in colouration (Fig. 6).

Colouration in life: based on an uncollected individual Fig. 7, background colour grey to light brown with broad undulating bands. Each band on the trunk has a dark brown border encompassing the pale colouration within. Head light brown with white and black patches on its dorsum; a clear pale whitish band from canthus rostralis to a little behind the eye.

Comparison with other Hemidactylus: The new species may be distinguished from Indian and Sri Lankan Hemidactylus on the basis of (differing or non-overlapping character states indicated parenthetically): dorsal scalation on trunk, granular, intermixed with enlarged, fairly regularly arranged longitudinal rows of 18-20 trihedral, moderately keeled, striated tubercles of equal size on dorso-lateral aspect, 2-3 rows of tubercles on mid-dorsum smaller in size, about two dorsal granular scales wide (dorsal tubercles absent or, if present, rounded, smooth, or feebly keeled, not regularly arranged in $H$. frenatus, $H$. garrnotii, $H$. leschenaultii, $H$. flaviviridis, $H$. platyurus, $H$. aquilonius, $H$. giganteus; conical tubercles not arranged in longitudinal series in $\mathrm{H}$. karenorum; SVL of at least $91.7 \mathrm{~mm}$ (SVL less than $80 \mathrm{~mm}$ in $H$. gracilis, $H$. karenorum, $H$. reticulatus, $H$. depressus, $H$. albofasciatus, $H$. parvimaculatus, $H$. sataraensis, $H$. pieresii, $H$. scabericeps, $H$. robustus, $H$. persicus, $H$. triedrus, $H$. brookii, $H$. turcicus, $H$. treutleri, $H$. gujaratensis).

Only five members of the genus Hemidactylus from India and Sri Lanka have a SVL of greater than or equal to $90 \mathrm{~mm}$. These include $H$. maculatus, $H$. prashadii, $H$. aaronbaueri, $H$. graniticolus and $H$. hunae. Hemidactylus acanthopholis sp. nov. can be distinguished from Hemidactylus aaronbaueri by the presence of 19-21 femoral pores on each side separated by 13-14 pore-less scales (vs. 15-19 femoral pores on each side separated by 6 poreless scales) in males, and 18-20 rows of regularly arranged, enlarged trihedral, moderately keeled, striated tubercles on dorsum in Hemidactylus acanthopholis sp. nov. (vs. 18-20 rows of irregularly arranged, enlarged, 
domed and feebly keeled tubercles on dorsum). The new species can be distinguished from $H$. prashadi by the presence of 19-21 femoral pores on each side separated by 13-14 poreless scales (vs. 17-20 femoral pores separated by three pore-less scales) in males.

The new species is similar in size and general appearance to Hemidactylus maculatus, $H$. hunae and $H$. graniticolus however differs from these by having dorsal trunk with granular scales intermixed with enlarged, fairly regularly arranged longitudinal rows of 18-20 trihedral, moderately keeled, striated tubercles of equal size (size of tubercles about four dorsal granular scales in width) on dorsolateral aspect, 2-3 rows of tubercles on mid-dorsal trunk smaller in size of about two dorsal granular scale width in (vs. back with conical, granular, striated scales intermixed with enlarged, fairly regularly arranged longitudinal rows of 16-18 sub-trihedral, weakly keeled, striated tubercles in $H$. granaticolus and $H$. hunae [Fig. 3]); dorsal pholidosis of tail with small, imbricate, striated scales intermixed with large rounded un-keeled tubercles, scales sub-equal throughout and a series of eight enlarged, moderately keeled and weakly striated and flattened tubercles (vs. small, imbricate, striated scales and a series of four enlarged, keeled and weakly striated and flattened tubercles in $H$. granaticolus [Fig. 4]); femoral pores in males 19-21 on each side separated by 13-14 poreless scales (Fig. 5) (vs. 16-19 femoral pores on each side with a gap of 5-9 pore-less scales in H. maculatus; 22-24 femoral pores on each side with a gap of 3-6 scales in H. hunae; 2328 femoral pores on each side separated by $1-3$ scales in $H$. graniticolus); two large and one small internsal present between supranasals (vs. two large internasals in $H$. maculatus and $H$. granaticolus). Furthermore Hemidactylus acanthopholis sp. nov. differs from $H$. sykesii, (junior synonym of $H$. maculatus) in bearing 19-21 femoral pores in males on each side separated by $13-14$ pore-less scales (vs. 20 femoral pores separated medially by 6 pore-less scales). Differs from $H$. subtriedrus, a putative junior synonym of $H$. triedrus by having SVL 91.7-108mm (vs. SVL 76mm); total femoral pores 39-42 (vs. range of 12-28 in H. triedrus), see Jerdon (1853), Mahony (2011), and Smith (1935).
Hemidactylus acanthopholis sp. nov. differs from Hemidactylus sp. (=Hemidactylus cf. maculatus sensu Javed et al., 2011) from Andhra Pradesh by having 19-21 femoral pores on each side separated by 13-14 pore-less scales (vs. 21-25 on each side separated medially by $4-5$ pore-less scales) and lamellae on digit IV of pes 10-12 (vs. 12-14).

Distribution and natural history: Colonel R. H. Beddome collected specimens from Tirunelveli (then known as Tinnevelly) from the Indian state of Tamil Nadu, southern India. Francis (1989) has provided a description of the extent of the district which covered parts of present day Tirunelveli and Thoothukudi districts. Tirunelveli was the headquarters of the district during Beddome's collection in the late 1800 s and likely the types too were collected from around the city. However, the preferred habitat of this species has largely been destroyed from the vicinity of the city due to agricultural practices. Based on published data, and supported from museum collection, this species certainly occurs in the eastern dry parts of Kalakkad Mundanthirai Tiger Reserve and Tirunelveli (Johnsingh, 2001; Vijayakumar et al., 2006; Pal S. and Deepak V. pers. comm.) and at Kallidaikurichi ca. $28 \mathrm{~km}$ south west of Tirunelveli city (Fig. 8, Deepak V. pers. comm.). In the outskirts of Kallidaikurichi, Banatheertham, and Courtallam the new species has been observed to take refuge under large boulders, and was active on these boulders after dusk (Deepak V. pers. observation). The habitat at Kallidaikurichi is of Southern Euphorbia Scrub type (RaviSankar, 2014) and largely degraded and with large boulders scattered in an open scrub landscape.

\section{Discussion}

Caranza \& Arnold (2006) established patterns of relationships among members of the genus Hemidactylus; however the study sampled only a few Indian endemics. This gap was largely filled by recent studies by Bansal \& Karanth (2010) and Bauer et al. (2010). Genetic data could not be derived for the new species as the scope of present study was restricted to museum material and hence phylogenetic affinity of the new species is discussed based on external morphology. Based on its large size and general morphological characters like markings, large keeled dorsal tubercles, and 
lamellae number, Hemidactylus acanthopholis sp. nov. appears morphologically most similar to $H$. maculatus from the Northern Western Ghats and perhaps $H$. granaticolus from south eastern Karnataka. Whereas Hemidactylus acanthopholis sp. nov., inhibits dry areas in southern Tamil Nadu, $H$. granaticolus and $H$. maculatus are found in wetter areas. Recent studies indicate that Hemidactylus maculatus is likely to be restricted to Northern Western Ghats of Gujarat and Maharashtra, and populations attributed to this species outside this region might in turn be cryptic species within the broadly distributed $H$. maculatus complex as supported by the elevation of $H$. hunae from the level of subspecies (Bauer et al., 2010), the descriptions of Hemidactylus acanthopholis sp. nov. and $H$. granaticolus (Agarwal et al., 2011), and the occurrence of yet another potentially undescribed taxa in Andhra Pradesh (Javed et al., 2011). Having examined the type series of Hemidactylus acanthopholis sp. nov. from Tirunelveli (=Tinnevelly) Agarwal et al. (2011) regarded these specimens to be conspcific with $H$. maculatus. In order to prevent future confusion, we wish to clarify that the paratype BMNH 1946.8.23.67, cited as a female by Agarwal et al. (2011) is herein confirmed to be an adult male with a clear series of femoral pores.

Table 1: Morphometric and meristic data for Hemidactylus acanthopholis sp. nov., L, left; R, right; *broken.

\begin{tabular}{|c|c|c|c|c|c|}
\hline \multirow[b]{2}{*}{ Character } & \multicolumn{3}{|c|}{ males } & \multicolumn{2}{|c|}{ females } \\
\hline & $\begin{array}{c}\text { BMNH } \\
\text { 1946.8.23.68 } \\
\text { holotype }\end{array}$ & $\begin{array}{c}\text { BMNH } \\
1946.8 .23 .67 \\
\text { paratype }\end{array}$ & $\begin{array}{c}\text { ZSI } \\
12429 \\
\text { paratype }\end{array}$ & $\begin{array}{c}\text { BMNH } \\
\text { 1946.8.23.69 } \\
\text { paratype }\end{array}$ & $\begin{array}{c}\text { BNHS } \\
1670 \\
\text { paratype }\end{array}$ \\
\hline SVL & 91.7 & 82.2 & 108.6 & 85.5 & 79.8 \\
\hline TRL & 36.0 & 30.3 & 46.7 & 35.1 & 36.7 \\
\hline BW & 20.1 & 17.7 & 25.7 & 20.5 & 14.7 \\
\hline CL & 17.3 & 17.0 & 21.2 & 15.1 & 14.0 \\
\hline TL & 114.3 & 71.3 & $9.9 *$ & 58.4 & $84.0 *$ \\
\hline TW & 11.5 & 11.2 & 12.4 & 12.2 & 8.0 \\
\hline HL & 21.1 & 18. & 29.6 & 19.0 & 23.6 \\
\hline HW & 21.1 & 19.6 & 25.5 & 19.1 & 15.1 \\
\hline $\mathrm{HH}$ & 12.3 & 13.8 & 15.3 & 12.1 & 8.6 \\
\hline FL & 15.2 & 14.8 & 16.4 & 13.9 & 11.9 \\
\hline OD & 6.3 & 5.3 & 6.9 & 6.0 & 5.0 \\
\hline $\mathrm{NE}$ & 8.2 & 7.8 & 12.0 & 7.2 & 7.2 \\
\hline SE & 11.9 & 10.4 & 13.3 & 10.3 & 9.4 \\
\hline $\mathrm{EE}$ & 7.1 & 7.4 & 9.3 & 6.0 & 5.0 \\
\hline EL & 3.4 & 2.5 & 3.5 & 3.1 & 2.8 \\
\hline IN & 2.3 & 2.1 & 2.8 & 2.3 & 3.0 \\
\hline $\mathrm{IO}$ & 8.8 & 7.5 & 9.4 & 8.3 & 7.2 \\
\hline Lamellae (L manus) & $10-11-11-11-11$ & $10-11-11-11-12$ & $10-11-11-11-11$ & $10-11-11-11-11$ & $10-11-10-12-12$ \\
\hline Lamellae ( $\mathrm{R}$ manus) & $10-11-11-11-11$ & $10-11-11-11-11$ & 10-11-11-11-11 & $10-11-11-11-11$ & $10-11-12-11-12$ \\
\hline Lamellae (L pes) & $10-11-11-11-10$ & $10-11-11-11-10$ & $09-11-12-12-11$ & $09-11-12-12-11$ & $10-12-12-11-10$ \\
\hline Lamellae (R pes) & $10-11-11-11-11$ & $10-11-11-11-11$ & $09-11-12-12-11$ & $09-11-11-10-11$ & $10-12-11-11-10$ \\
\hline Supralabials (L/R) & $9 / 8$ & $10 / 9$ & $9 / 9$ & $10 / 9$ & $9 / 10$ \\
\hline Infralabials (L/R) & $8 / 8$ & $8 / 8$ & $8 / 8$ & $9 / 9$ & $8 / 8$ \\
\hline Pores (L/R) & $19 / 20$ & $19 / 21$ & $21 / 21$ & - & - \\
\hline $\begin{array}{l}\text { Gap of pore-less } \\
\text { scales }\end{array}$ & 14 & 13 & 12 & - & - \\
\hline
\end{tabular}

Based on present knowledge and understanding, all species in the maculatus group appear to be allopatric and each inhibits a unique ecological region with no apparent range overlap. Given that the present study was based on museum material, collection of fresh material is necessary to enable an assessment ofmorphological variation within the species and provide molecular data to elucidate its phylogenetic affinity. The description of the new species merely reflects the need for more rigorous surveys across India to evaluate hidden diversity, especially within wide ranging species, and a detailed study of the long ignored synonyms of each species should be undertaken to establish which of these 
names are likely to represent valid species (see Mahony, 2011; Zug et al., 2007).

\section{Acknowledgments}

Authors were able to visit the BMNH through a travel grant from the Newby Trust Limited to $\mathrm{ZM}$. The present work would not have been possible without the help of the following institutions: BMNH, Madras Crocodile Bank Trust (Mahabalipuram) and National Centre for Biological Sciences (Bangalore). For logistic support we acknowledge The Gerry Martin Project. David Gower, Patrick Campbell (BMNH), Director (ZSI), Kaushik Deuti (ZSI) and B. H. C. K. Murthy (ZSI) are acknowledged for hosting us and granting access to specimens in their collection. Special thanks are due to Saunak Pal and Deepak Veerappan for their help with specimens, photographs and locality data plus constant support throughout the preparation of this manuscript. Robert Drewes and David Blackburn are thanked for help with images of the specimens housed in the herpetology collection of the Californian Academy of Sciences, San Francisco. S. M. Maqsood Javed helped with literature and data on specimens from Andhra Pradesh for which we pay him our deepest gratitude. Varad Giri and Stephen Mahony provided valuable comment and review from which the manuscript greatly benefited.

\section{Literature cited}

Amarasinghe, A. A. T., A. M. Bauer, I. Ineich, J. Rudge, M. M. Bahir, and D. E. Gabadage, 2009. The original descriptions and figures of Sri Lankan gekkonid lizards (Squamata: Gekkonidae) of the 18th, 19th and 20th centuries. Taprobanica, 1: 83-106.

Agarwal, I, V. B. Giri, and A. M. Bauer, 2011. A new cryptic rock-dwelling Hemidactylus (Squamata: Gekkonidae) from south India. Zootaxa, 2765: 21-37.

Bauer, A. M., T. R. Jackman, E. Greenbaum, V. B. Giri, and A. de Silva, 2010. South Asia supports a major endemic radiation of Hemidactylus geckos. Molecular Phylogenetics and Evolution, 57: 343-352.

Bauer, A. M., R. Vyas, T. R. Jackman, A. Lajmi, and V. B. Giri, 2012. Hemidactylus porbandarensis Sharma, 1981 is a synonym of
Hemidactylus robustus Heyden, 1827. Hamadryad, 36: 46-51.

Bansal, R. and K. P. Karanth, 2010. Molecular phylogeny of Hemidactylus geckos (Squamata: Gekkonidae) of the Indian subcontinent reveals a unique Indian radiation and an Indian origin of Asian house geckos. Molecular Phylogenetic \& Evolution, 57:459-65.

Bansal, R. and K. P. Karanth, 2013. Phylogenetic analysis and molecular dating suggest that Hemidactylus anamallensis is not a member of the Hemidactylus radiation and has an ancient late cretaceous origin. Plos One, 8: e60615.

Batuwita, S. and R. Pethiyagoda, 2012. Rediscovery of the Sri Lankan 'house gecko' Hemidactylus pieresii Kelaart (Reptilia: Gekkonidae) with a redescription of Hemidactylus depressus Gray. Zootaxa, 3359: 17-30.

Carranza, S. and E. N. Arnold, 2006. Systematics, biogeography, and evolution of Hemidactylus geckos (Reptilia: Gekkonidae) elucidated using mitochondrial DNA sequences. Molecular Phylogenetic \& Evolution, 38: 531-545.

Deraniyagala, P. E. P., 1937. A new gecko Hemidactylus maculatus hunae. Ceylon Journal of Science, 20: 185-189.

Francis, W., 1989. Gazetteer of South India (2 Volumes). Mittal publication, New Delhi: 536.

Giri, V. B., 2008. A new rock dwelling Hemidactylus (Squamata: Gekkonidae) from Maharashtra, India. Hamadryad, 32: 25-33.

Giri, V. B. and A. M. Bauer, 2008. A new ground-dwelling Hemidactylus (Squamata: Gekkonidae) from Maharashtra, with a key to the Hemidactylus of India. Zootaxa, 1700: 21-34.

Giri, V. B, A. M., Bauer, R. Vyas, and S. Patil, 2009. New species of rock-dwelling Hemidactylus (Squamata: Gekkonidae) from Gujarat, India. Journal of Herpetology, 43: 385393.

Javed, S. M. M., S. Saravanan, F. Tampal, and C. Srinivasulu, 2009. Occurrence and comparison of Jerdon's Gecko Hemidactylus subtriedrus Jerdon 1853 with Termite Hill Gecko Hemidactylus triedrus (Daudin 1802) from Ananthagiri Hills, 
northern Eastern Ghats, India. Journal of Threatened Taxa, 1: 366-369.

Javed, S. M., Z. A. Mirza, C. Srinivasulu, B. H. C. K. Murthy, and F. Tampal, 2011. A Divergent Population of Hemidactylus maculatus maculatus Duméril et Bibron, 1836 (Reptilia: Sauria: Gekkonidae) from the Northern Eastern Ghats, India. Russian Journal of Herpetology, 18: 7-16.

Jerdon, T. C., 1854. Catalogue of the Reptiles inhabiting the Peninsula of India. Part 1. Journal Asiatic Society of Bengal, 22: 462-479.

Johnsingh, A. J. T., 2001. The KalakadMundanthurai Tiger Reserve: a global heritage of biological diversity. Current Science, 80: 378388.

Mahony, S., 2009. A new species of gecko of the genus Hemidactylus (Reptilia: Gekkonidae) from Andhra Pradesh. Russian Journal of Herpetology, 16: 27-34.

Mahony, S., 2011. Taxonomic revision of Hemidactylus brookii Gray: a re-examination of the type series and some Asian synonyms, and a discussion of the obscure species Hemidactylus subtriedrus Jerdon (Reptilia: Gekkonidae). Zootaxa, 3042: 37-67.

Mahony, S. and G. R. Zug, 2008. Hemidactylus karenorum (Squamata, Gekkonidae) in India. Hamadryad, 32, 84-86.

McMahan, C. D. and G. R. Zug, 2007. Burmese Hemidactylus (Reptilia, Squamata, Gekkonidae): geographic variation in the morphology of Hemidactylus bowringii in Myanmar and Yunnan, China. Proceedings of the Californian Academy of Science, 58: 485-509.

Purkayastha, J., D. Madhurima, A. M. Bauer, S. Sengupta, and S. K. Dutta, 2010. Notes on the Hemidactylus Bowringii complex (Reptilia: Gekkonidae) in India, and a change to the national herpetofaunal list. Hamadryad, 35: 2027.

Ravi-Sankar, L., 2014. Forest Administration in Tirunelveli District 1950 to 1995. Manonmaniam Sundaranar University, Tirunelveli: 261.

Smith, M. A., 1935. The Fauna of British India, Including Ceylon and Burma. Reptilia and Amphibia. Vol. II - Sauria. Taylor and Francis, London: 440.
Uetz, P. and J. Hošek, 2013. The Reptile Database <http://www.reptile-database.org>, accessed on 23 April, 2014.

Vijayakumar S. P., A. Ragavendran, and C. B. Choudhury, 2006. Herpetofaunal assemblage in a tropical dry forest mosaic of Western Ghats, India: Preliminary analysis of species composition and abundance during the dry season. Hamadryad, 30: 41-54.

Zug, G. R., J. V. Vindum, and M. S. Koo, 2007. Burmese Hemidactylus (Reptilia, Squamata, Gekkonidae): taxonomic notes on tropical Asian Hemidactylus. Proceedings of the California Academy of Sciences, Fourth Series, 58: 387-405.

\section{Appendix I}

Hemidactylus aaronbaueri: Holotype BNHS 1739 (male), Ghatghar, Taluka Junnar, Pune District, Maharashtra, India; ZSI 21648A and ZSI 21648C (female), ZSI 21648B (male), Bhairavgadh fort, Taluka Karjat, Pune District, Maharashtra, India.

Hemidactylus albofasciatus: Paratype ZSI 21109 (female), Dorle village, Rajapur Taluka, Ratnagiri District, Maharashtra, India; two males BNHS 1579 and 1582 Dabhil-Ambere, Ratnagiri District; Maharashtra, India.

Hemidactylus bengaliensis $(=H$. flaviviridis): Syntype ZSI 5780, Bengal.

Hemidactylus flaviviridis: ZSI 20963 (male) Jaipur, Rajasthan, India; ZSI 21688 (female) Udaipur, Rajasthan, India.

Hemidactylus hunae: Type specimen BMNH 1946.8.23.77 (female), Okanda, Eastern Province, Sri Lanka.

Hemidactylus giganteus: Syntype, BMNH 1877.8.6.5 (male), Godaari valley near Bhadrachalam, Andhra Pradesh, India.

Hemidactylus gracilis: Syntype, ZSI 5190 (male), from 'S.E. Berár' (in Madhya Pradesh, India; BNHS 1591 (male) and BNHS 1592 (female), Chatushringi hills, Pune, Maharashtra, India.

Hemidactylus graniticolus: Holotype BNHS 1850 (female), hills near Harohalli, Bangalore Rural district, Karnataka, India; paratypes BMNH 1946.8.23.70 (female), BMNH 1946.8.23.71 (female), BMNH 1946.8.23.72 (male), BMNH 1946.8.23.73 (female), BMNH 1946.8.23.74 (female), BMNH 1946.8.23.75 (female), Salem District, Tamil Nadu, India; BMNH 1946.8.23.76 (male), 'Malabar', India.

Hemidactylus gujaratensis: Holotype BNHS 1818 (female) Vagheshwari Mata Temple, Junagadh City, Junagadh District, Gujarat, India.

Hemidactylus kelaartii: Syntypes ZSI 2617 (male) and ZSI 2618 (female), from 'Ceylon' (= Sri Lanka). 
Hemidactylus maculatus: BMNH 1956.1.11.41 (female), Matheran, Raighad District, Maharashtra, India; ZSI 25608 (male) Government rest house, Panchagani, Satara District, Maharashtra, India; BNHS 74 (female) and BNHS 75 (female), Mumbai, Maharashtra, India; BNHS 1086 (male), Kanheri caves, Mumbai, Maharashtra, India.

Hemidactylus marmoratus (=Hemidactylus leschenaulti): Holotype, ZSI 5058, from 'S. E. Berár, near Chánda' Maharashtra, India.

Hemidactylus persicus: Holotype, ZSI 5961, from 'Persia' (= Iran). The register lists the type as from 'Shiraz, Persia'.

Hemidactylus platyceps (=Hemidactylus gracilis): Holotype, ZSI 17020, from 'Bilimora, Bombay Presidency' Gujarat, India.

Hemidactylus prashadi: BNHS 147 (male), Shiroli forest, Belgaum North Kanara, Karnataka, India; BNHS 146 (male), Gersoppa falls, North Kanara, Karnataka, India; ZSI 20123 (female) neighbourhood of Jog, N. Kanara district, Bombay Presidency' (at present in Karnataka, India.

Hemidacrtylus reticulatus: Type specimens BMNH 1874.4.29.410 (male) and BMNH 1874.4.29.411 (female), Kollegal, Karnataka, India.

Hemidactylus sataraensis: Holotype BNHS 1743 (female) Chalakewadi, Satara District, Maharashtra, India; paratype BNHS 1742 (female); non-type BNHS 2288 (male), BNHS 2289 (female), Chalakewadi, Satara District, Maharashtra, India.

Hemidactylus scabriceps: Type specimens, ZSI 15353, from 'Rámanád', Tamil Nadu State, India.

Hemidactylus sp. (H. cf. maculatus/H. subtriedrus): ZSI 24155 (female), Bastar District, Chhattisgarh, India; ZSI 25866 (male) Tyda railway station, Tyda, Vishakapatnam district, Andhra Pradesh, India; ZSI 25708 (male) Ganjam district, Odisha, India; a large male without locality and registration tag along with ZSI 25708.

Hemidactylus sykesii (=H. maculatus): Type specimen, BMNH XXII.20a (male), Deccan, India (Donated by Indian Museum XXII.20a).

Hemidactylus tenkatei $(=H$. subtriedroides $)$ : Lectotype, BMNH 1946.8.25.54/ZSI 4135, "Tsagain, Upper Burma".

Hemidactylus treutleri: Holotype ZSI 25711 (male), paratype ZSI 25712 (female), outer stone wall of Golconda Fort, Hyderabad, Andhra Pradesh, India.

Hemidactylus triedrus: ZSI 17054 (female) Travindrum, Kerala, India; ZSI 5852, ZSI 5853 (males), Bangalore, Karnataka, India; ZSI 21483, ZSI 21486 (males), Pune, Maharashtra, India 


\section{PLATE 3}

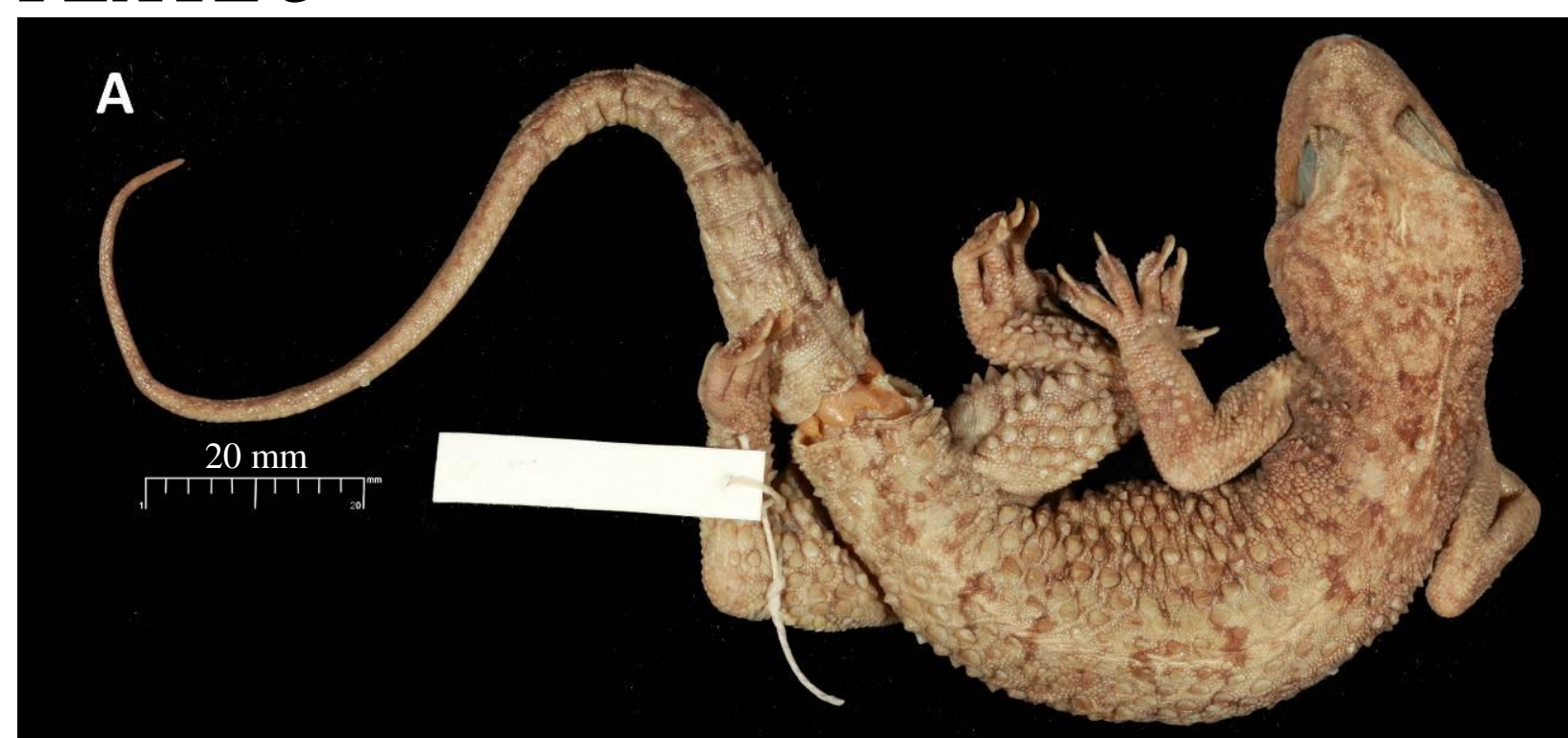

B

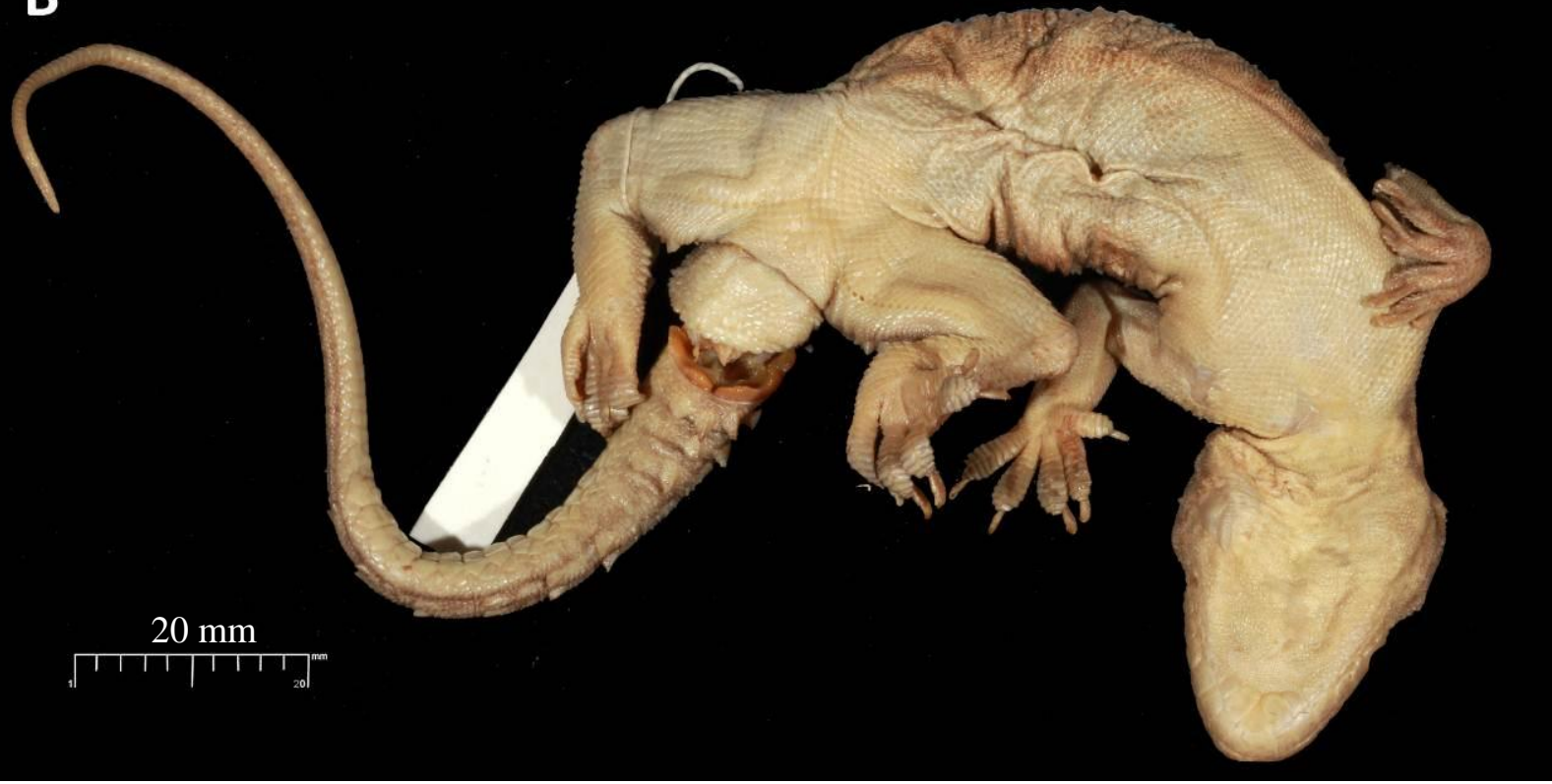

Figure 1: Holotype (BMNH 1946.8.23.68) of H. acanthopholis sp. nov., A, dorsal aspect; B, ventral aspect.

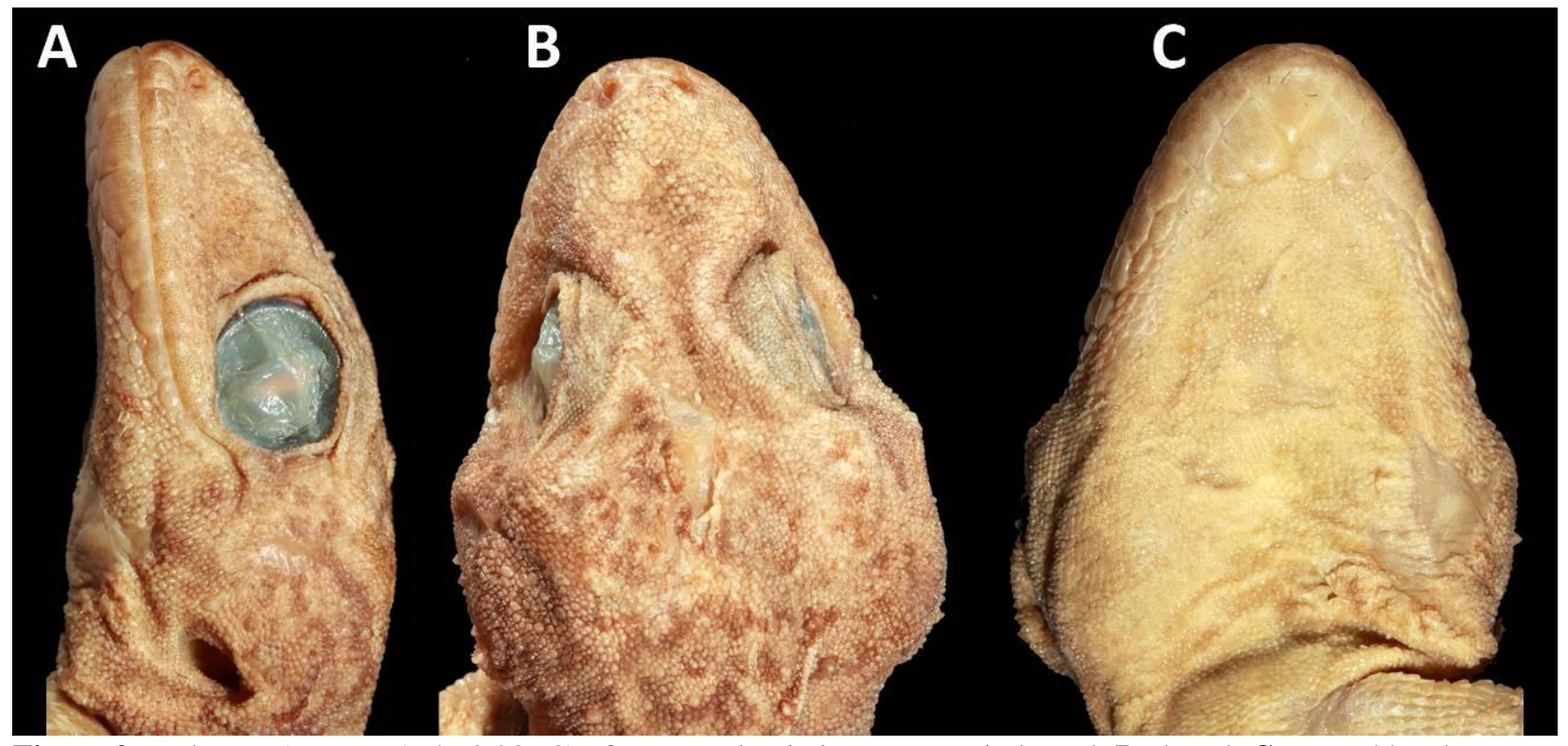

Figure 2: Holotype (BMNH 1946.8.23.68) of H. acanthopholis sp. nov., A, lateral; B, dorsal; C, ventral head. 


\section{PLATE 4}

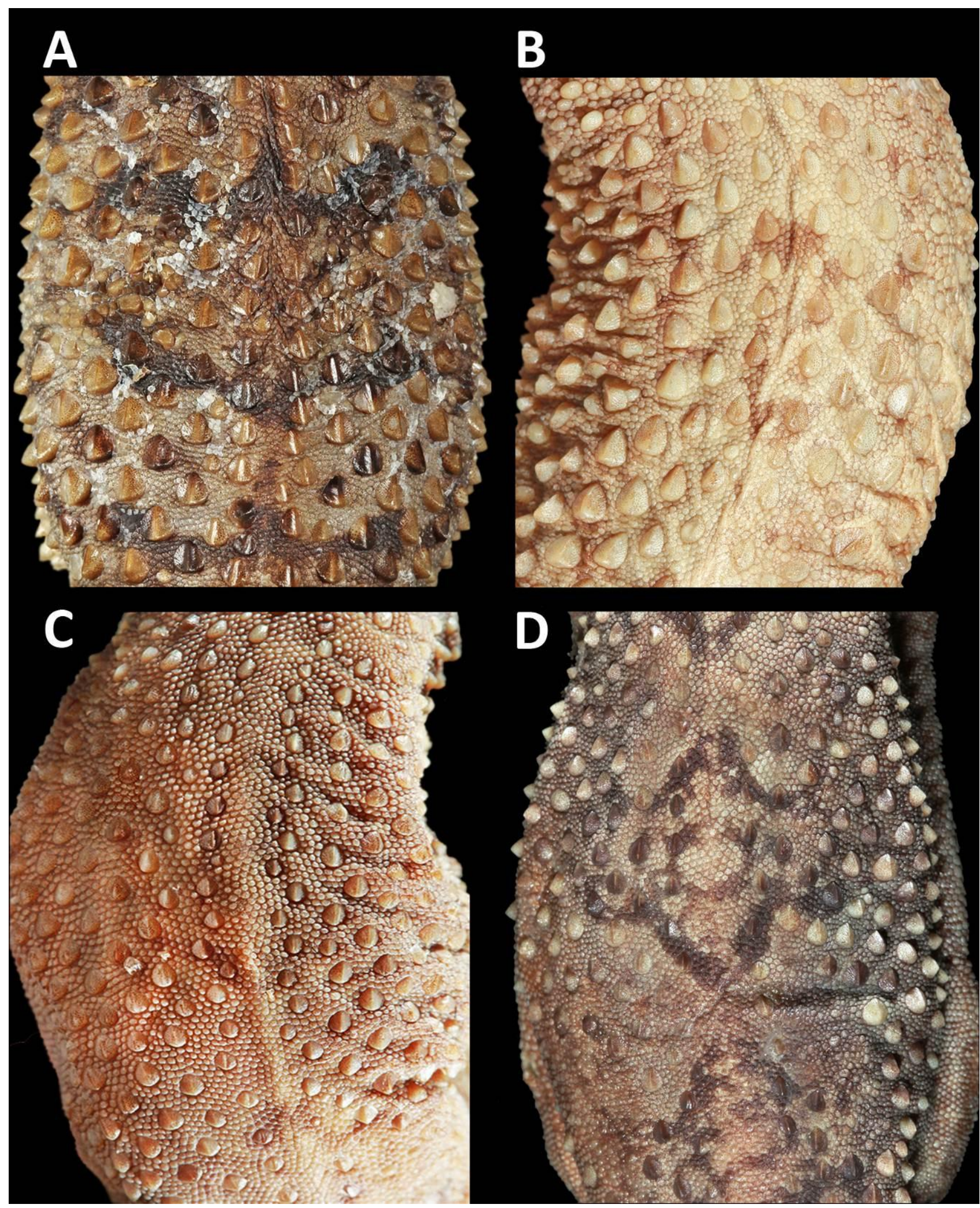

Figure 3: Dorsal view of trunk; A, H. maculatus (BMNH 1956.1.11.41); B, H. acanthopholis sp. nov. (BMNH 1946.8.23.68); C, H. granaticolus (BMNH 1946.8.23.72); D, H. hunae (BMNH 1946.8.23.77) 


\section{PLATE 5}

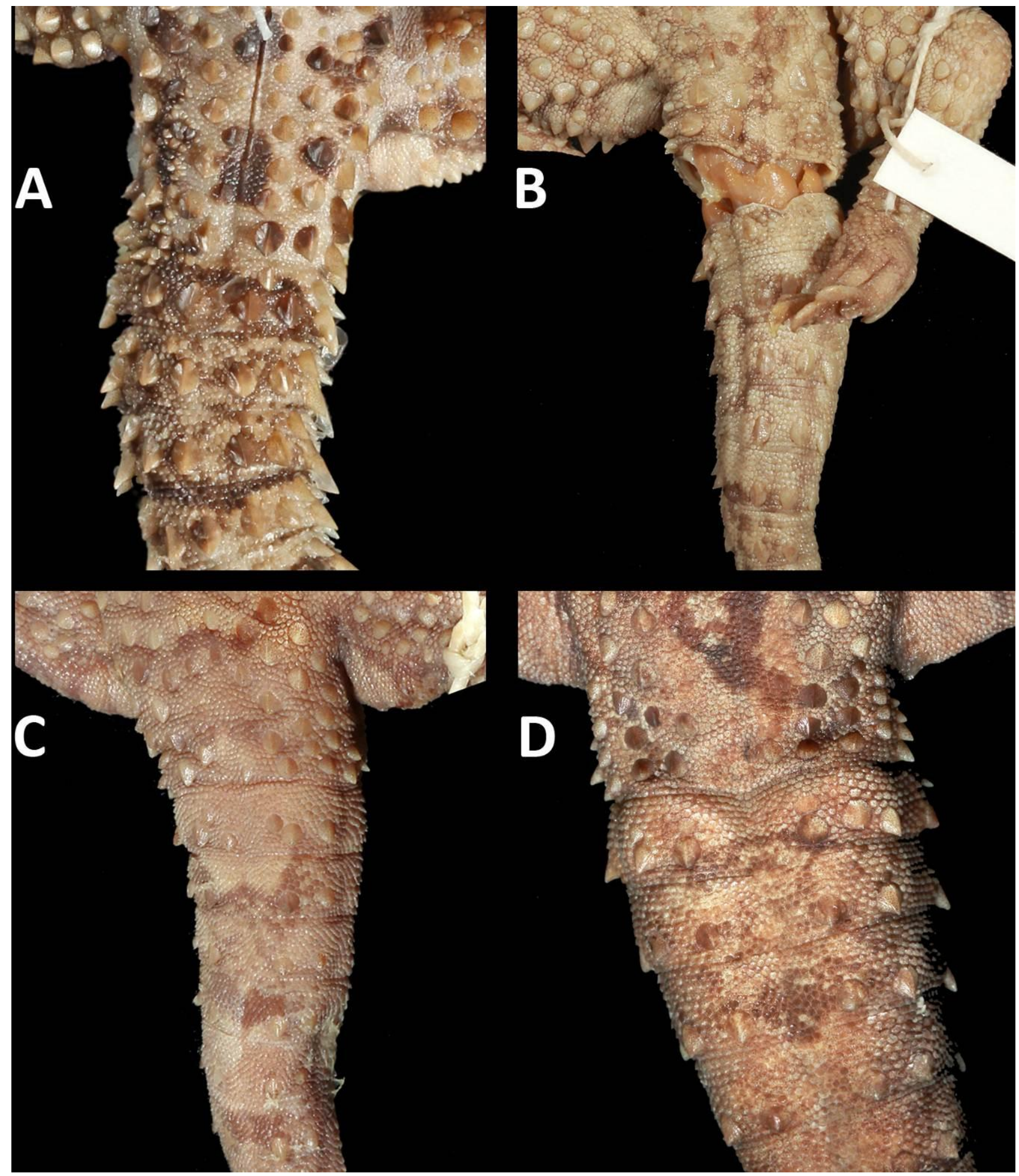

Figure 4: Dorsal view of caudal base; A, H. maculatus (BMNH 1956.1.11.41); B, H. acanthopholis sp. nov. (BMNH 1946.8.23.68); C, H. granaticolus (BMNH 1946.8.23.72); D, H. hunae (BMNH 1946.8.23.77) 


\section{PLATE 6}

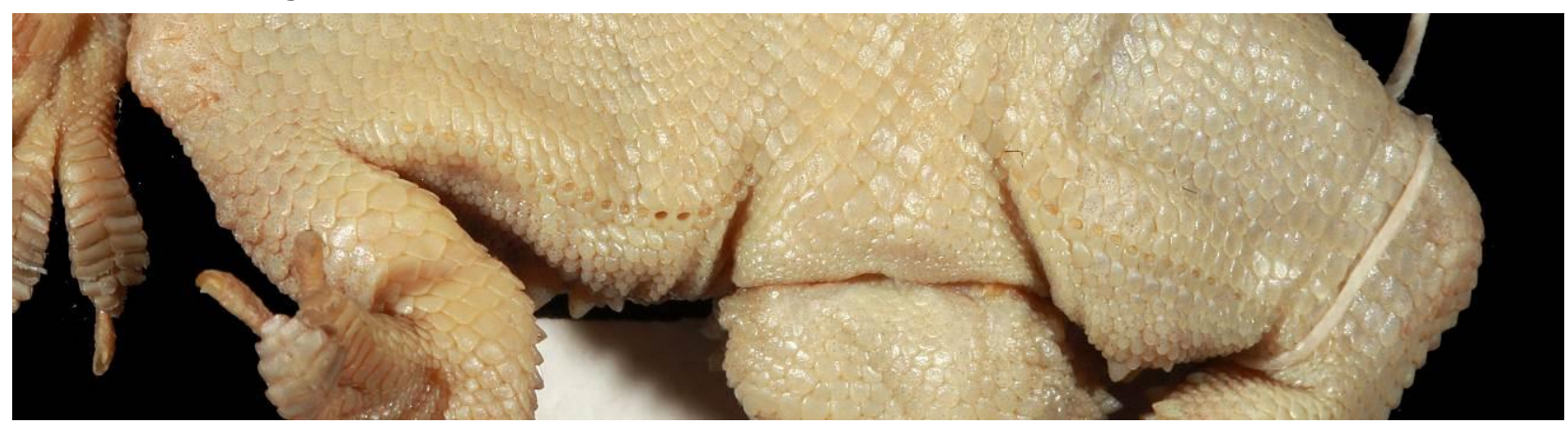

Figure 5: Holotype (BMNH 1946.8.23.68) of H. acanthopholis sp. nov. showing cloaca region and femoral pores.

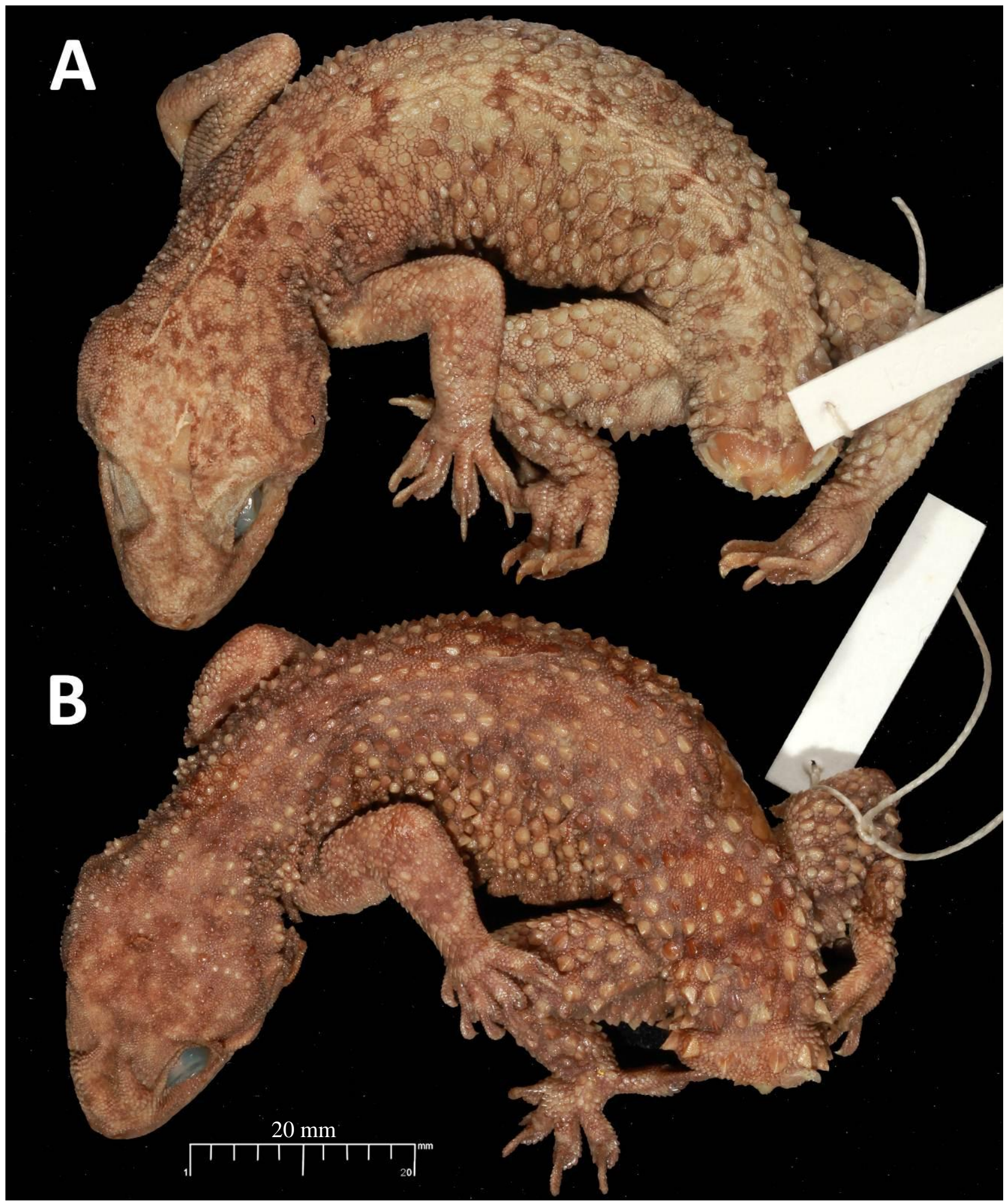

Figure 6: H. acanthopholis sp. nov. paratypes; A, male (BMNH 1946.8.23.67); B, female (BMNH 1946.8.23.69) 


\section{PLATE 7}

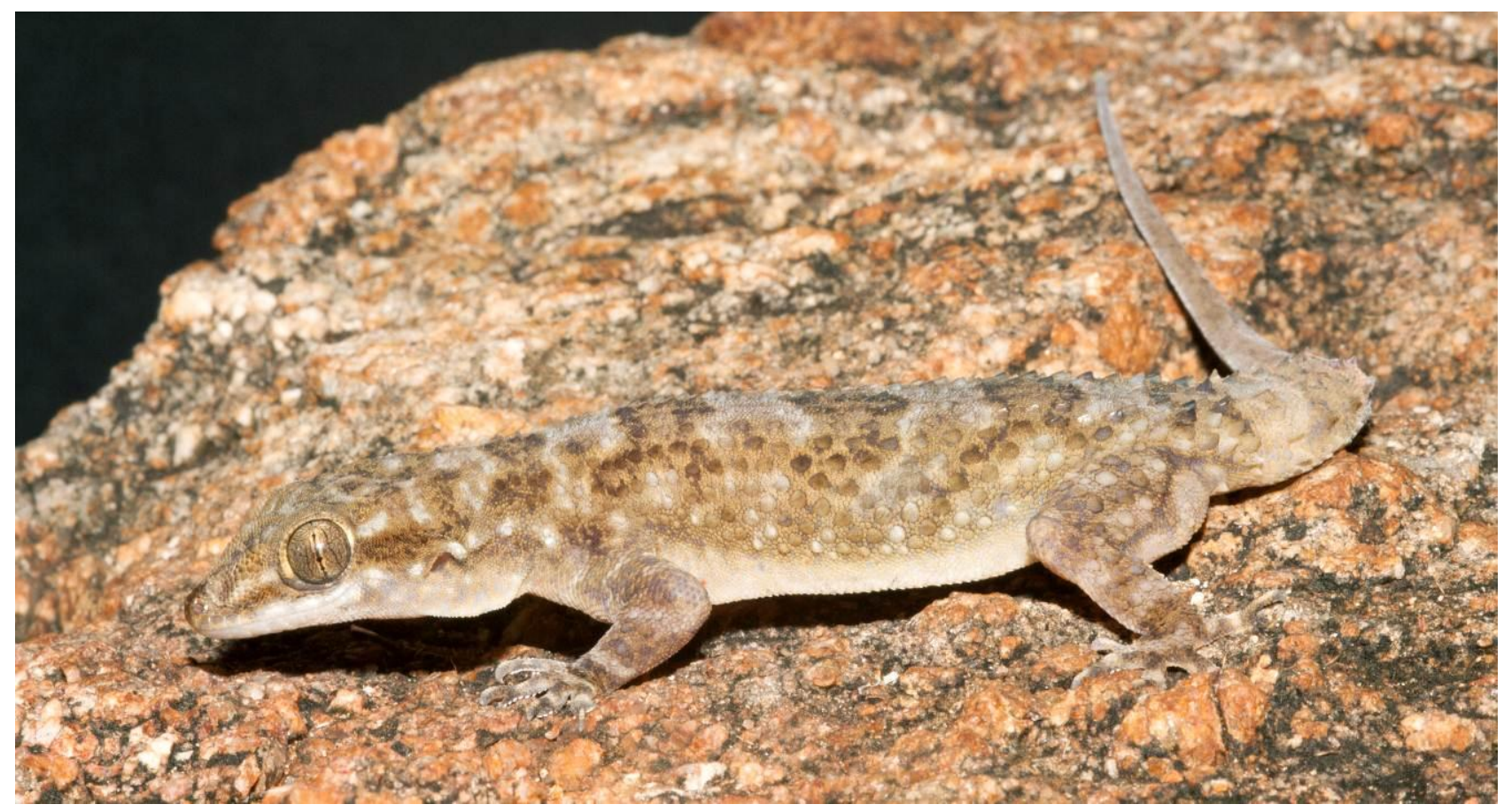

Figure 7: An uncollected individual of $H$. acanthopholis sp. nov. from Kallidaikurichi, India (Photo V. Deepak).

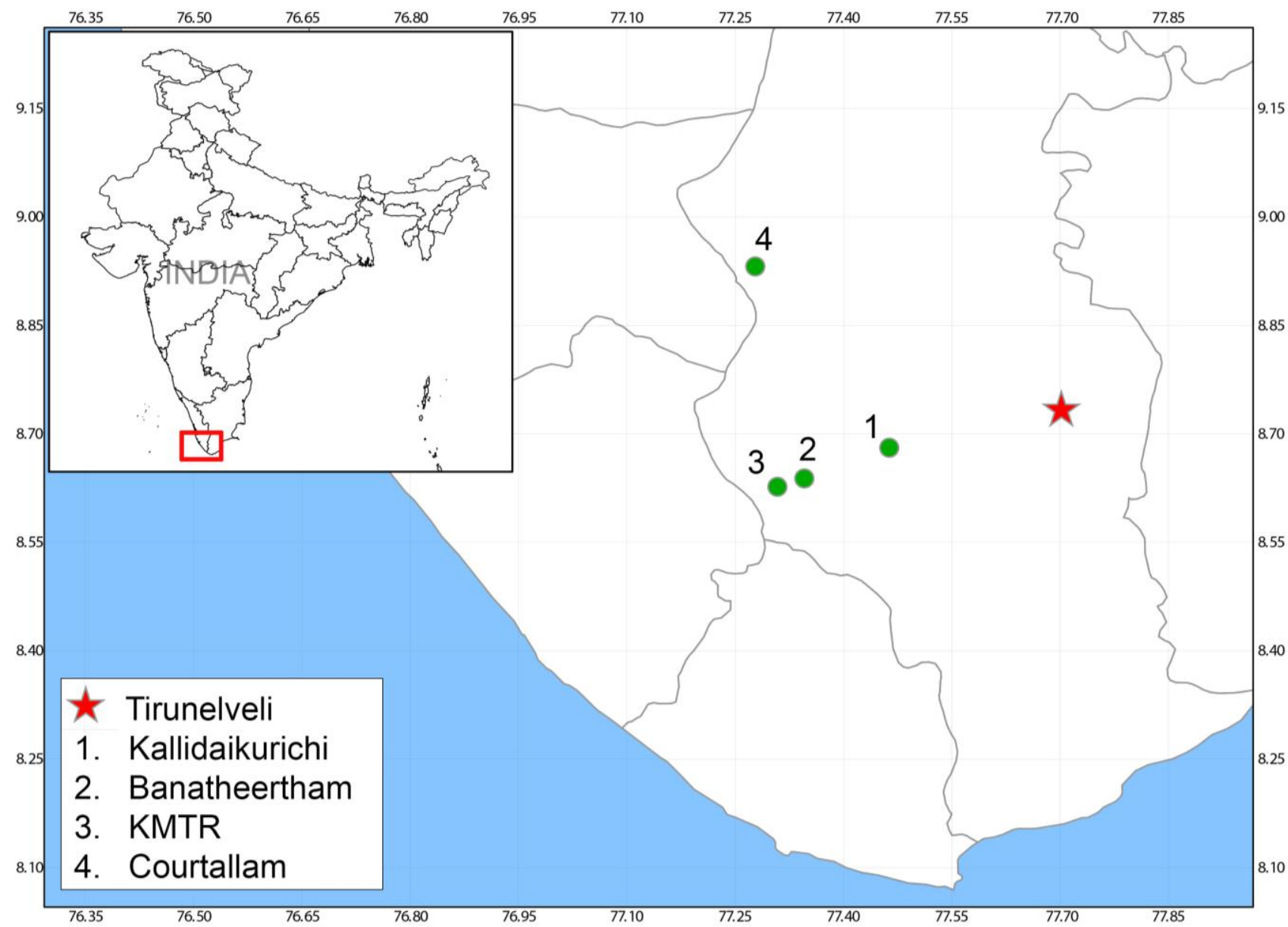

Figure 8: Map showing type locality in a red star and other known localities for H. acanthopholis sp. nov. 